Dos, paseos por los bosques narrativos (un lugar para la ficción)

\title{
El pesimismo de Schopenhauer en Borges: una herencia cristiana en común
}

\author{
Plante, Claudia
}

Claudia Plante Sobre la autora

Universidad Clermont Auvernia, Argentina

El hilo de la fábula

Universidad Nacional del Litoral, Argentina

ISSN: $1667-7900$

ISSN-e: 2362-5651

Periodicidad: Anual

vol. 19 , núm. 21, 2021

revistaelhilodelafabula@fhuc.unl.edu.ar

Recepción: 30 Abril 2021

Aprobación: 29 Junio 2021

DOI: https://doi.org/10.14409/hf.v0i21.10561
Resumen: Este trabajo tiene como objetivo demostrar que el pesimismo de Schopenhauer, muy difundido en la obra de Borges, es de raigambre profundamente cristiana. Tras evidenciar las semejanzas entre las ideas cristianas y schopenhauerianas, se analizará en qué medida Borges las integra a su obra o se distancia de ellas.

Palabras clave: Borges, Schopenhauer, Cristianismo, Pesimismo, Pecado original.

Abstract: This paper aims to demonstrate that Schopenhauer's pessimism, very pervasive in Borges' work is deeply rooted in Christianism. After showing the similarities between the Christian and Schopenhauerian ideas, the extent to which Borges integrates them to his work or distances himselffrom them will be analized.

Keywords: Borges, Schopenhauer, Christianism, Pessimism, Original Sin.

\section{Introducción}

En muchas ocasiones confesó Borges su admiración por Schopenhauer, ${ }^{1}$ cuya filosofía había logrado, según el argentino, «expresar en palabras» el enigma del universo (Borges, 1999:46). La influencia de Schopenhauer es tal vez más notable en la literatura que en la filosofía, probablemente por la impecabilidad de su estilo y la preminencia concedida por él al arte. Su pensamiento no sedujo tan solo a Borges sino a Wagner, Nietzsche, Kafka, Mann y Freud por citar a algunos. Por supuesto, son muchas otras las lealtades de Borges y el escritor no fue únicamente atraído por la filosofía de Schopenhauer; lo que sí suscitó su curiosidad fue la metafísica en general, calificada famosamente por él de «rama de la literatura fantástica» (OC I: 436). ${ }^{2}$ Cierto es que la metafísica schopenhaueriana le pareció fascinante y, aún más, valiosa desde el punto de vista estético, o sea, transferible al dominio del arte, y en su caso la literatura. Su profesada admiración por el filósofo se debe, entre otras cosas, a unos intereses comunes, en especial por la cultura indostánica y las religiones del Extremo Oriente como el hinduismo o el budismo, a cuyo descubrimiento en Europa contribuyó grandemente Schopenhauer. Pero más allá de esa misma atracción por el Oriente, los vincula una concepción similar del mundo y del ser humano que puede interpretarse como una forma de pesimismo, por lo menos en ciertos aspectos. La cultura oriental fue justamente 
interpretada a través de este prisma pesimista e incluso nihilista en Europa; ${ }^{3}$ cosa, nos parece, imputable al influjo ejercido por el cristianismo en el Occidente. ${ }^{4}$ El cristianismo histórico, cuya influencia sigue notable pese a la secularización de Occidente, bebe esencialmente de dos fuentes: la tradición judía y la filosofía griega. Podríamos considerar el pesimismo bastante ajeno al judaísmo, religión matriz del cristianismo, y más propio de la mentalidad griega, pero se puede decir que los padres de la Iglesia «cristianizaron» el contenido del pensamiento griego y que, a raíz de esa hibridación, propusieron una lectura bastante pesimista de la Biblia tanto vetero como neo-testamentaria. La cultura cristiana compartida por Schopenhauer y Borges, por mucho que se declare ateo el primero y agnóstico el segundo, no ha dejado de incidir en nuestros esquemas de pensamiento, y eso, pese a que la institución eclesiástica sea mucho menos poderosa al día de hoy. Ambos autores destacan además por su gran conocimiento de las Escrituras y por haber sabido aprovecharlas para ilustrar sus ideas. Sostenemos que el pesimismo manifestado tanto en Schopenhauer como en Borges no deriva tanto de su interés común por la sabiduría oriental sino de su adscripción a la cultura occidental, moldeada en gran parte por la religión cristiana a lo largo de los siglos.

En este trabajo se buscará, ante todo, delinear el pesimismo borgeano a la luz del pensamiento cristiano y el de Schopenhauer. Cabe desbrozar la hipótesis planteada, esto es, interrogarse sobre los elementos vinculados con el cristianismo y Schopenhauer que puedan justificar la adjudicación de una tonalidad pesimista a la obra de Borges.

Veremos que el pesimismo borgeano presenta afinidades manifiestas con el del cristianismo y el de Schopenhauer por dos razones fundamentales, que son: en primer lugar, la constatación de la inautenticidad del mundo y de la vida que este posibilita; en segundo lugar, la idea de un Mal ineludible y consubstancial al hombre.

\section{La insignificancia del hombre en la Tierra}

\section{a) El aferramiento egoista a una vida desprovista de interés}

A la persona de Cristo se le ha hecho defender muchas causas, muchas veces sacando palabras suyas fuera del contexto evangélico. Shaw, por mucho que lo reconozca (Shaw, 1916:466), considera que la cosmovisión de Jesús, cuyos contornos se pueden trazar a la lectura de los Evangelios, es, con todo, esencialmente pesimista (Shaw, 468-69). Dicho pesimismo se vio reforzado por San Pablo y los grandes representantes de la patrística, sobre todo por integrar el dualismo platónico a la religión cristiana. ${ }^{5}$ Por supuesto, al decir esto no se nos olvida que el símbolo primordial del cristianismo es el de la Trinidad, cuyo misterio fue el objeto de los primeros Concilios y que suscitó la perplejidad de Borges. ${ }^{6}$ No podremos tratar este tema debidamente dadas las limitaciones de este trabajo, en donde nos interesamos más bien en la persistencia extraña del ya referido dualismo, más propio del helenismo en el seno del cristianismo heterodoxo, la religión del Dios Trino. Este dualismo, muy arraigado en la cultura occidental, por ser esta muy tributaria del cristianismo, implica un recelo e incluso un franco desprecio hacia lo carnal y lo mundano. La lectura paulina del 
Evangelio da a pensar que tal recelo se justifica por la superficialidad del hombre que cifra la autenticidad de la vida en el cumplimiento sistemático de sus deseos que satisfacen «la carne» y no el espíritu. ${ }^{7}$ Asimismo, el discurso de Cristo parece dibujar una frontera infranqueable entre el reino de Dios y la Tierra, donde la vida misma es insignificante y el hombre que lucha por prolongarla, como si no hubiera otra vida más auténtica, revela su pobreza espiritual. ${ }^{8}$ En ese sentido, el amor a la vida implica una deslealtad para con Dios y un aferramiento a los bienes materiales mientras que el cristianismo insta a serle más bien desleal al mundo. Salvando todas las distancias, se puede decir que Schopenhauer concuerda con muchos planteamientos cristianos, pues en su filosofía se observa igualmente una desconfianza marcada hacia el mundo y un pesimismo respecto a la humanidad. Partiendo de la dicotomía kantiana entre fenómeno y cosa en sí, establece una distinción entre el mundo como representación y el mundo como voluntad. Pero, la diferencia establecida por el pensador alemán es muy relativa, ya que nuestra percepción del mundo está, según él, conformada por los principios de razón y de individuación que ciñen la representación humana al estrecho marco espacio-temporal. Nos representamos el mundo como un conjunto de fenómenos, pero detrás de este velo, sostiene Schopenhauer, impera una única sustancia: la Voluntad de la que manan todas las calamidades que afectan a los hombres. Haciéndose eco del mensaje cristiano, el filósofo se esmera en desarraigar de la mente humana la creencia en la felicidad en un mundo cuya índole indefectiblemente maligna comparte desgraciadamente el mismo hombre, fenómeno entre los fenómenos. Quizá puede decirse, según él, que la llamada «felicidad» se confunde con una sensación placentera muy breve, un alivio efímero del dolor que nos atormenta continuamente:

[...] Toda felicidad es de naturaleza meramente negativa y no positiva, [...] precisamente por eso no puede ser una satisfacción y dicha duradera sino una simple liberación de un dolor o una carencia, a la que ha de seguir un nuevo dolor o un languor, un vacío anhelo y un tedio. (Schopenhauer 2009: 378)

\section{b) La inmortalidad en Borges como simbolo del deseo irracional}

La inanidad de todo cuanto existe y de toda aspiración humana se manifiesta magistralmente en El inmortal de Borges (OC I: 533). El protagonista del cuento, también narrador autodiegético del relato de segundo grado, tiene todas las características del hombre común, tal y como lo presentan el cristianismo y Schopenhauer, cuyo egoísmo, perfectamente admisible en cualquier sociedad humana, lleva a desdeñar la tranquilidad de una vida juzgada por él aburrida en pos de aventuras que estimulen su desear. Es, efectivamente, el tedio que despierta el repentino interés del protagonista llamado Flaminio Rufo, tribuno romano de la época de Diocleciano, y lo lleva a dar crédito a la extravagante historia que le cuenta un jinete, según el cual existiría un río ubicado en una misteriosa Ciudad cuyas aguas le darían al hombre la inmortalidad. Al emprender la busca de la «Ciudad de los Inmortales», Rufo da muestras de un egoísmo disparatado ya que la inmortalidad en este mundo fenomenal corresponde a la satisfacción del mayor de los deseos. Este se vería automáticamente reprobado tanto por Cristo como Schopenhauer en la medida en que se trataría de prolongar infinitamente una vida mediocre, volcada hacia lo material y el placer del cuerpo, cosas corruptibles 
y efímeras que no eximen del sufrimiento y hacen del hombre un sujeto débil a merced de sus propias pasiones. El periplo de Flaminio Rufo representa, en clave metafórica, cualquier trayectoria vital jalonada por el aburrimiento y el dolor con breves momentos dichosos. Borges llena el relato de evocaciones simbólicas de la dimensión irrisoria de la existencia humana regida por el deseo, el cual viene a ser el origen del mal en la perspectiva cristiana o la manifestación psicológica de la Voluntad en cada individuo según Schopenhauer. El inmortal nos permite intuir la dimensión de la felicidad que no es sino una sensación placentera, muy efímera y ante todo muy subjetiva, tan insignificante e ilusoria como el mismísimo mundo. La insatisfacción constante de Rufo se puede entender ya que el protagonista, como cualquier hombre, se siente momentáneamente feliz en el aquí y ahora, lo cual se opone a la Eternidad prometida por el Dios cristiano. En su genial uso de la adjetivación y su tratamiento del tiempo, Borges logra transmitir la imagen de una existencia penosa como si de un largo proceso laborioso se tratara, entrecortado por efímeros momentos de satisfacción. La vida no se confunde con el Paraíso inmarcesible prometido por las Escrituras, sino que está hecha de un presente escurridizo y mortífero: «ein Stätes Sterben», como lo dice muy pertinentemente Schopenhauer (Salter, 1911:279).

De este tiempo tan agobiante, el hombre tampoco puede prescindir; lo necesita como si le fuera esencial y, al negarse a reconocer su dimensión artificial con la experiencia del tedio, aún más insoportable para muchos que el dolor, se aferra a él de manera tan enfermiza que busca llenarlo con distracciones irrisorias, lo que Pascal llamara «divertissement». Finalmente, al muy humano Rufo, la ansiada inmortalidad resulta terriblemente decepcionante ya que él anhela la existencia garantizada por la mortalidad ${ }^{9} \mathrm{y}$, más profundamente, intuye que la vida eterna no es posible en un mundo cuya esencia es el conflicto, la alternancia constante entre dolor y tedio, o sea la Voluntad. No por otra razón le dijo Cristo a Pilato que ese mundo no era el suyo ${ }^{10}$ y no por otra razón Schopenhauer identificó la inmortalidad con la «perpetuación de un error» (Vilchis, 2003:140) pues, según él, no en otro lugar que en este mundo se había inspirado Dante para crear su Infierno: «Woher denn anders hat Dante den Stoff zu seiner Holle genommen, als aus dieser unserer wirklichen Welt?\#» (Salter, 1911:277). El afán individual por conquistar la inmortalidad revela el poder de manifestación de la Voluntad en un solo hombre pero, de hecho, lo que le falta al individuo, la especie lo tiene garantizado, como lo explica Schopenhauer:

Que generación y muerte se han de considerar como algo perteneciente a la vida y esencial a ese fenómeno de la voluntad se deriva de que ambos se nos presentan como las expresiones sumamente potenciadas de aquello en lo que consisten todas las restantes formas de vida. Esta no es, en efecto, más que un continuo cambio de la materia bajo la firme persistencia de la forma: y precisamente eso es la mortalidad de los individuos en la inmortalidad de la especie. (Schopenhauer, 2009:333)

Cada hombre lucha frenéticamente por preservar y prolongar su propia existencia, muchas veces a costa de vidas ajenas, algo que Cristo hubiera reprobado - con su exhortación a amar al prójimo- pero que permitió paradójicamente que se perpetuara la raza humana. La inmortalidad se ve así como una calamidad, como el resultado de una ignominia de la que estamos todos secretamente conscientes. Como Flaminio Rufo, el individuo es tan insensato 
que llega al extremo de desear esta inmortalidad para sí mismo, con desprecio de las necesidades de los que lo rodean.

\section{c) Una divergencia notable respecto al suicidio}

$\mathrm{Al}$ adoptar las perspectivas cristiana y schopenhaueriana, uno puede sentirse aliviado de que la vida en este mundo desolado, «la selva selvaggia» de Dante, tenga un fin y de que la inmortalidad no pase de un mero mito. Pero, si bien dicha inmortalidad no constituye ninguna solución para el hombre arrojado, por así decirlo, a la existencia, de igual modo tanto Schopenhauer como el cristianismo reprueban con vehemencia el suicidio. Podría esperarse que una visión trágica de la vida implicara una exaltación del suicidio como lo hiciera el griego Hegesias. No obstante, la Iglesia considera el suicidio moralmente inaceptable y lo cuenta entre los pecados mortales por ser un incumplimiento del segundo mandamiento «No matarás» (Biblia Reina Valera, Éxodo, 20:13) así como una actitud irrespetuosa para con Dios, ya que el que procura quitarse la vida olvida que esta cae bajo la jurisdicción divina. Por haberse atrevido a violar el curso de la naturaleza, los suicidas del Infierno dantesco se ven rebajados a la más primaria forma de vida, la vegetal: como Pier Delle Vigne, cuyo suicidio fue motivado por haber sido falsamente designado como traidor. Como lo explica muy bien Janis Vanacker, Dante ilustra con maestría el posicionamiento de la Iglesia respecto a los suicidas; por un lado, son unas víctimas de la injusticia que gobierna el mundo, pero al mismo tiempo, son culpables por dejarse llevar por el sufrimiento que experimentan:

\footnotetext{
In a place like Hell the question of being guilty or innocent is an important issue. Seen from this perspective, the story of Pier delle Vigne is a strange case because he can be considered innocent and guilty at the same time. On the one hand, Pier declares that he had not committed treachery (cf. Inf. 13, 73-75) when he was alive. Though the reader does not know whether Pier says the truth or not, he realizes that the chancellor, who was blinded and sent to prison, must have suffered a lot [...] On the other hand, Pier cannot deny that, by committing suicide, he deliberately broke the laws of God. Although he hoped «to escape from scorn» («fuggir disdegno», Inf. 13, 71) he must have been aware that, by killing himself, he committed a Christian sin. (Vanacker, 2010: 11).
}

Desde la perspectiva cristiana, el suicida es algo así como un Job impaciente, incapaz de aguantar el dolor lo bastante como para integrarlo en una mayor perspectiva que abarque el sufrimiento universal.

Sorprendentemente, Borges no es tan categórico respecto al suicidio al cual alude en su obra de manera mucho más ambigua. El autor examina incluso su compatibilidad con el cristianismo en el atrevido ensayo dedicado al libro de John Donne titulado El Biathanathos (OC II: 78), en donde el poeta inglés sostiene que el suicidio no puede constituir ningún pecado al tratarse, en algunas circunstancias, de un acto de pura caridad, lo que lo aproximaría al martirio. Donne se atreve a plantear que, siendo Dios, Cristo hubiera podido no morir y consideró además que nadie hubiera podido provocar su muerte sin su aceptación de esta. $\mathrm{Al}$ «dar su vida por las ovejas» (OC II: 80), Cristo ofreció generosamente su vida sin pensar en su propia persona lo que, para Donne, debería verse como un «suicidio» desinteresado y altruista. Borges remata esta tesis controvertida al 
sugerir, siguiendo a Mäinlander, que la divinidad de Jesús y su consubstancialidad con el Dios trinitario lleva forzosamente a pensar que su muerte ya estaba decidida incluso antes de que se creara el Mundo:

Quizá el hierro fue creado para los clavos y las espinas para la corona de escarnio y la sangre y el agua para la herida. Esa idea barroca se entrevé detrás del Biathanatos. La de un dios que fabrica el universo para fabricar su patíbulo. (OC II: 80).

Más allá de la generosidad que podría incentivar el candidato al suicidio, se evoca en Borges otro motivo de suma importancia y que delata en su pensamiento las huellas del estoicismo, del filósofo escocés David Hume y de la cultura japonesa. Desde esta perspectiva, el valorar negativamente el suicidio es tan arbitrario como el valorar positivamente la conservación de la vida, en cualquier situación. Coincidiendo con Schopenhauer respecto a la primacía del principio vital en la especie humana, Borges suscribe la idea de que cualquier ser humano llevando una vida feliz y honrada desea evidentemente prolongarla. Sin embargo, para el argentino, es totalmente admisible que una persona de bien, insatisfecha con su existencia, tome la decisión de ponerle término pues el hombre, al haber dejado el reino animal para inscribirse en la cultura, puede legítimamente preferir la dignidad a la vida. De manera que Borges no reprueba a su amigo Francisco López Merino, en cuyo suicidio no ve una elección fácil y precipitada sino una decisión autónoma y racional como lo sugiere el primer cuarteto del poema dedicado al joven:

Si te cubriste, por deliberada mano, de muerte

Si tu voluntad fue rehusar todas las mañanas del mundo

Es inútil que palabras rechazadas te soliciten, predestinadas a imposibilidad y a derrota [...] (OC I: 93).

Lo que sí condena Borges es el sufrimiento injusto del cual Francisco fue víctima, el mundo miserable que no estuvo a la altura de sus necesidades para vivir dignamente:

Solo nos queda entonces

decir el deshonor de las rosas que no supieron demorarte,

el oprobio del día que te permitió el balazo y el fin. (OC I: 93).

Respecto al carácter irreversible de la pérdida del honor, Borges citaba con mucha emoción el caso de su abuelo paterno, gran militar argentino, quien, al ser consciente de la inminencia de la derrota prefirió morir a manos del enemigo. ${ }^{11}$ Para el escritor porteño, la renunciación heroica a una vida con una esposa y dos hijos pequeños demostraba la valentía del abuelo a la par que recalcaba la cobardía de su nieto por la que este estaba seguro pecar, incapaz de quitarse una vida que él mismo consideraba infeliz. El suicidio, en la opinión de Borges, revela la grandeza del ser humano muy consciente de la nimiedad del lugar que ocupa en el Cosmos y del cual no tardará en ser destituido, por lo que su acto no puede interpretarse como una deserción sino como una jubilación merecida. Descreyendo, en la estela de Hume, de la noción de identidad personal, Borges da a entender tanto en El Bianthanatos como en su poema a López Merino que, si el «yo» elabora diariamente una existencia ficcional, tal vez sea más pertinente para cualquiera que experimente el agobio del escritor con falta de inspiración, ponerle punto final. ${ }^{12} \mathrm{~A}$ lo mejor este último acto permite darle un sentido magistral a una vida 
absurda y mediocre; la muerte por suicidio permite así adquirir algo de libertad, el control sobre la vida que le está naturalmente vedado al ser humano. Asimismo, Borges le da al suicidio una dimensión artística en la medida en que la muerte elegida por el individuo cobra mucha más importancia que su propia vida y le permite definirse como quiere que los demás lo definan y recuerden. De manera que la muerte de López Merino tiene la frescura y la inocencia infantil que lo caracterizaban:

[...] tal vez a imagen de la predilección, obramos la muerte, que la supiste de campanas, niña y graciosa,

hermana de tu aplicada letra de colegial, y que hubieras querido distraerte en ella como en un sueño. (OC I: 93)

De igual manera, no tuvo que conocer Borges a su abuelo personalmente como para saberlo imbuido del espíritu del militar, comparable al del samurái, despidiéndose de la vida con el seppuku. ${ }^{13}$

\section{Un hombre vendido al «Adversario»}

a) La historia de siempre, la «[...] de Cain / que sigue matando a Abel» (OC II 334)

La lucidez de Cristo acerca de la naturaleza humana no fue óbice para que se empeñara en enseñar una serie de principios muy difíciles de poner en práctica para el hombre común. René Girard analiza con gran pertinencia los textos evangélicos que ofrecen, según él, una muy buena ilustración del funcionamiento psicológico humano; en concreto, el pensador francés elabora a partir de las Escrituras su teoría del mecanismo sacrificial, ${ }^{14}$ según la cual la tendencia mimética de cada individuo ${ }^{15}$ lo llevaría a imitar e incrementar la violencia de otros hombres, hasta desembocar en el surgimiento del caos cuya única resolución es el sacrificio, decidido colectivamente, de un miembro de la sociedad, «el chivo expiatorio». ${ }^{16}$ Schopenhauer concibe igualmente el mundo $\mathrm{y}$, a menor escala, toda sociedad como un polvorín a punto de explotar, donde reina un estado de guerra permanente de todos contra todos, siguiendo en eso a Hobbes (Schopenhauer, 2009:392). Respecto a las relaciones interpersonales, Schopenhauer duda mucho de su carácter desinteresado; en su opinión, el otro es un enemigo, un estorbo o, lo que es tal vez peor, un mero medio para satisfacer unos deseos personales como lo recalca Salter:

Most men know, Schopenhauer observes, innumerable sufferings of others in their vicinity, but do not set about mitigating them, because this would involve some selfdenial on their part. If we meet a stranger, our first thought is apt to be, «Can he be of use to us?» (Salter, 1911:277).

El nuestro vendría a ser un mundo donde los hombres, inmersos en una búsqueda egocéntrica de glorificación de sí mismos, compiten entre sí y sufren mezquinamente del triunfo ajeno. El odio y la envidia se convierten en el pan de cada día para los miembros de una sociedad en donde se aspira al ensalzamiento del Yo. Aquello no puede más que fomentar el odio en una comunidad en 
constante riesgo de desagregarse; en la Epístola de Santiago, se evidencia el peligro asociado con la envidia:

Pero si tenéis envidia amarga y contención en vuestros corazones, no os gloriés, ni seáis mentirosos contra la verdad:

Que esta sabiduría no es la que desciende de lo alto, sino terrena, animal, diabólica.

Porque donde hay envidia y contención, allí hay perturbación y toda obra perversa. (Santiago, 14-16)

Al echar mano de la figura mítica del «doble», Borges da una perfecta ilustración de la hostilidad natural entre los hombres, observada tanto por el cristianismo como por Schopenhauer. Dicho tema cobra mucha importancia en uno de los famosos cuentos del argentino, Los teólogos, en donde se describe la animosidad experimentada por un teólogo cristiano hacia otro en la época del Imperio Romano. No pretendemos, en los límites que nos impone el formato de nuestro trabajo, agotar las lecturas del cuento que son múltiples, pero es de advertir que lo que dijimos anteriormente, respecto al cristianismo y Schopenhauer, encaja perfectamente con las características del protagonista, llamado Aureliano. Este, un teólogo al servicio de la Iglesia, intenta derribar todo movimiento herético susceptible de hacer peligrar la unidad del cristianismo. Como es de esperar, dado el tema que nos ocupa, su enemigo acérrimo no es ningún hereje sino otro defensor de la ortodoxia, Juan de Panonia. Entendemos que el motivo del odio no es otro que la envidia de Aureliano hacia Juan, siendo este mucho más talentoso que aquél. Lo observado por Philonenko en su libro sobre Schopenhauer permite entender que un resentimiento tan fuerte se explica por la vigorosa manifestación de la Voluntad en cada individuo, provocando que este último no admita que otro posee lo que a él le falte. ${ }^{17}$

Lo que dice Girard, reclamándose del cristianismo, es muy esclarecedor para entender la reacción de Aureliano y el desencadenamiento fatal de los hechos que componen la intriga. El rencor de Aureliano se exacerba tras ser, por enésima vez, humillado por Juan, quien logra rebatir de manera mucho más convincente que el protagonista las tesis heréticas de la «secta de los anulares». El narrador recalca lo grotesca que resulta la refutación redactada por Aureliano, quien, muy consciente de su inferioridad respecto a Juan, según refiere el narrador, presenta a las autoridades eclesiásticas algo deliberadamente ridículo. Valiéndonos del esquema girardiano, podríamos decir que Juan constituye para Aureliano un rival y un modelo; lo que él anhela para sí, inspirado por el Adversario diría Girard (1983: 242), es el carisma de Juan. No admite que el trabajo de su rival sea tan ejemplar y, a sabiendas del éxito de su enemigo, decide exagerar su propia incompetencia con el único propósito de diferenciarse aún más de él. La búsqueda de una personalidad original, admirada por los demás es un tema muy trillado en Borges; pensamos naturalmente en las palabras recriminatorias que Shakespeare le dirige a Dios al quejarse de no saber exactamente cómo definir su personalidad en Everything and Nothing (OC II: 181). Pero, como lo explica muy bien Girard al describir las relaciones humanas a la luz del Evangelio, cuanto más el individuo lucha por diferenciarse del prójimo odiado, más acaba pareciéndose a él, dada la misma ambición que ambos comparten: el reconocimiento y la admiración de todos por lo que son. ${ }^{18}$ La envidia ilustra esta paradoja del ser humano que desea distinguirse del rival al tiempo que sueña con ocupar su lugar; lo cual no deja de ser ridículo, como lo señala Philonenko, siguiendo a Schopenhauer, «car lui, 
c'est lui, et moi c'est moi» (Philonenko, 1980:224). El individuo desea de alguna manera conservar su conciencia de existir como individuo y simultáneamente «absorber» los rasgos del carácter del otro que juzga atrayentes por el efecto que éstos generan sobre los demás. El odio de Aureliano se incrementa conforme va progresando el relato, lo que lo lleva a hacer pasar a su rival como un hereje ante la Iglesia, como si, ante la imposibilidad de suplantar a un enemigo fatalmente insustituible, la única alternativa estribara en eliminarlo.

\section{b) La culpa compartida}

Al leer a Borges, nos parece que el mal es de una «banalidad» tal que nadie de buena fe puede seriamente asombrarse de que algunos individuos muy de frecuentar cometan actos reprobables, en particular cuando pueden sacar provecho de ello. A la lectura de cuentos como Los teólogos o La forma de la espada, inferimos igualmente que, por mucho que se mienta el hombre, tanto los justos como los malvados sufren y ambos por último mueren. Schopenhauer habla al respecto de «justicia eterna» de la Voluntad. La expresión schopenhaueriana deja asomar mucha ironía, ya que está claro que la Voluntad no es para nada «justa»: ella se puede identificar con la «naturaleza maligna» de Leopardi que actúa cruel y ciegamente, de tal manera que, el mal que resulta, según pensamos, de un horrible cúmulo de circunstancias es, al contrario, irrevocablemente necesario. ${ }^{19}$

En la teología agustiniana se encuentra una explicación que resultó muy persuasiva a Schopenhauer, mucho más que todo intento de teodicea de parte de teólogos o filósofos y cuya huella es profunda en el corpus borgeano. Partiendo de la constatación de que el mundo y el hombre que le pertenece están ambos empañados por el mal, Agustín infiere que todos somos colectivamente culpables (Hippo, 2009:372). Aquello no deja de tener sentido para Schopenhauer, según quien las diferencias se dan en el mundo como representación. Las distinciones entre fenómenos son necesarias para interpretar racionalmente el mundo en el que vivimos, pero la razón no nos ayuda a entender que cada uno de nosotros estamos hechos, por así decirlo, «de la misma materia de los sueños», o sea que somos meras manifestaciones ilusorias de una Voluntad cuya malignidad llevamos en la carne.

Podemos aplicar lo que acabamos de decir al cuento anteriormente referido, Los teólogos. Aureliano logra sutilmente llevar a cabo su venganza y su rival, acusado de defender ideas heréticas, acaba muriendo en la hoguera. Fijémonos en una frase interesante del cuento: «Aureliano vio por primera y última vez el rostro del odiado» (OC, I: 555). La hendíadis entre los adjetivos ordinales sugiere hábilmente que se trata de un momento clave para Aureliano quien, no obstante, todavía cegado por el principio de individuación, no logra percibir lo evidente, un poco al modo de Percival, incapaz de reconocer el Santo Gral. Sin embargo, lo que se lee a continuación nos permite enterarnos de que Aureliano sintió una suerte de familiaridad, lo que no deja de ser extraño dado que, por mucho que aborrecía a Juan, tan solo lo conocía a través de sus escritos. Vamos entendiendo lo referido crípticamente por el narrador al enterarnos de las circunstancias de la muerte del teólogo envidioso, provocada por un incendio, o sea en las llamas del fuego como su enemigo. Pero, sobre todo, el proceso iniciado 
el día de la muerte de Juan se reanuda al encontrarse Aureliano, ya muerto, con Dios:

Aureliano supo que para la insondable divinidad, él y Juan de Panonia (el ortodoxo y el hereje, el aborrecedor y el aborrecido, el acusador y la víctima) formaban una sola persona. (OC, I: 556).

Aquí se advierte una verdadera anagnórisis: el odiado, la víctima de su mezquina envidia, no difería realmente de él. Incluso para Dios eran los mismos. Entendemos que lo trágico en la vida es el asunto de todos los hombres, hasta el más justo de ellos, porque, sugiere Borges siguiendo a Agustín, ${ }^{20}$ hay algo fundamentalmente malo en nosotros, algo cuyo origen no puede hallarse en un Dios benevolente (Hippo, 2009:347). Para Schopenhauer y San Agustín respectivamente, el inocente y el culpable proceden de la misma Voluntad o los une el mismo pecado.

\section{Conclusión}

Quisimos evidenciar el trasfondo pesimista de la obra de Borges y más concretamente, ubicar su postura en la línea de Schopenhauer; el deseo como parte íntegra de la psicología humana refleja en Borges el movimiento mismo del Mundo, lo que permite relacionar su cosmovisión con la de Schopenhauer que veía en todo, y en especial, en la capacidad volitiva del hombre, la obra de una Voluntad maligna. Tal pesimismo tiene que ver, en nuestra opinión, en muchos aspectos, con el cristianismo, en la medida en que Cristo se presenta como el redentor de una humanidad descarriada y fragmentada, compuesta de individuos vindicativos y egoístas. Las Escrituras dejan ya entrever una primacía del Mal por el cual siente el hombre una proclividad irremediable. «El estado de guerra» permanente, al cual Schopenhauer alude reclamándose de Hobbes, es el ritmo de la Naturaleza y asimismo el ritmo de toda existencia humana; esto indica un fallo, una imperfección del hombre desde el inicio de su historia en la Tierra. Por ello, Jesús reconoce, con la humildad y la lucidez que se le asocian, que sus palabras, cuya primera finalidad estriba en liberar a los hombres de un egoísmo enceguecedor y avasallante, han de caer, la mayoría de las veces, en terreno baldío. Aquello tampoco imposibilita la redención que sigue abierta al hombre, salvo que tal objetivo se puede conseguir por un camino más arduo que la mayoría de los hombres suelen evitar.

Este «escepticismo antropológico» (Mateos, 1998:123) es también el de Borges, en cuya obra la imagen del hombre es muy poco alentadora. Pero, nos pareció primordial subrayar una divergencia notable del argentino respecto a los planteamientos cristiano y schopenhaueriano; en ambos casos, la decisión de quitarse la vida constituye una manera descarada de afirmar el ego irrisorio. Lo hemos visto, probablemente bajo el influjo de otras fuentes, Borges se propone defender el suicidio en el que ve, al contrario, la posibilidad de adquirir, una vez muerto, la dignidad que la vida no le da a nadie.

El tema del fallo en la naturaleza humana daría motivo para amplias reflexiones; en efecto, no pudimos profundizar en la teología agustiniana, primordial en el cristianismo, dada la importancia dada a ciertos dogmas. Según Agustín, el hombre tiene verosímilmente una gran responsabilidad en la 
persistencia del Mal del cual es también víctima. La doctrina del pecado original, en especial, tiene mucha relevancia a la hora de identificar rastros del cristianismo tanto en Schopenhauer como en Borges, pero aquello tendría que ser el objeto de otro trabajo que podríamos proponer en el futuro.

\section{Referencias}

Biblia Reina Valera (2020). Origen.

Borges, Jorge Luis (1999). Autobiografía: 1899-1970. El Ateneo.

Borges, Jorge Luis (1989). Obras completas. Emecé.

Borges, Jorge Luis; Carrizo, Antonio (1982). Borges el memorioso. Fondo de Cultura Económica.

Girard, René (1983). Des choses cachées depuis la fondation du monde. Le livre de poche. Girard, René (2007). De la violence à la divinité. B. Grasset.

Hippo, Augustine of (2009). The city of God. Hendrickson Publishers, 2009.

Le Goff, Jacques; Truong, Nicolas (2015). Una historia del cuerpo en la Edad Media. Paidós.

Mateos, Zulma (1998). La filosofía en Jorge Luis Borges. Editorial Biblos.

Orsini, Christine (1986). La pensée de René Girard. Éditions Retz.

Orsini, Christine (2018). René Girard. Presses Universitaires de France.

Philonenko, Alexis (1980). Schopenhauer: une philosophie de la tragédie. Librairie Philosophique J. Vrin.

Salter, William (1911). Schopenhauer's Contact With Theology. Harvard Theological Review, 4, 271-310.

Schopenhauer, Arthur (2009). El mundo como voluntad y representación (trad. Ma. Pilar López de Santa). Trotta.

Schopenhauer, Arthur (2009). Parerga y paralipómena II. Trotta.

Shaw, Charles Gray (1916). The Pessimism of Jesus. International Journal of Ethics, 26(4), 466-81.

Steiner, George (1986). Les Antigones. Gallimard.

Rodríguez Monegal, Emir (1988).Jorge Luis Borges, a literary biography. Dutton.

Tasset, José Luis (1992). Suicidio y fiesta del yo. El suicidio como transgresión moral definitiva. A propósito de «on suicide» de David Hume. https://minerva.usc.es/ xmlui/handle/10347/5625.

Vanacker, Janis (2010). «Why Do You Break Me?» Talking to a Human Tree in Dante's. Neophilologus, 95(3), 431-45.

Vilchis, Javier (2003). Persona, educación y destino. Plaza y Valdes.

\section{Notas}

1 Para un estudio comparativo más profundizado entre la filosofía de Schopenhauer y la obra de Borges, ver Plante, (2018). Se puede consultar la biografía de Borges escrita por Emir Rodríguez Monegal en la que se menciona la revelación que constituyó para Borges su primer encuentro con la filosofía schopenhaueriana en la adolescencia (Rodríguez Monegal, 1988:139-140). Muchas referencias al filósofo salpican la obra entera del autor; en «Otro poema de los dones», Borges da las gracias por haber descubierto a Schopenhauer «que acaso descifró el universo» (OC 2:314). 
2 Haremos referencia a lo largo de este artículo a las Obras Completas de Borges de acuerdo a la abreviatura OC; se especificará, entre paréntesis, el volumen y las páginas correspondientes a las citas.

3 En el trabajo que dedicamos al libro de Sonia Betancort, Oriente no es una pieza de museo, aludíamos a la apropiación nihilista del acervo cultural oriental por el Occidente, fenómeno muy bien analizado por la autora. Cf. Plante, 2020: 6.

4 Sería un error atribuir, de manera taxativa, al cristianismo una doctrina morbosa y siniestra. Nos consta que el pesimismo es tan solo una dimensión de esta muy rica y antigua tradición religiosa; sobre todo, dicha postura pesimista ha ido modulándose a lo largo de la historia del cristianismo al cual adhieren personas cuyo fervor se debe sobre todo a la esperanza que les brinda su religión. No es nuestra intención alimentar la leyenda negra del cristianismo; asimismo, nos parece más acertado considerar esta religión como un conjunto cultural que abarca realidades de muy diversa índole, ya sea en el campo histórico, teológico, sociológico... El pesimismo que evidenciamos tiene mucho más que ver con determinados pasajes de las Escrituras y algunas doctrinas teológicas que, sin constituir la totalidad del vasto pensamiento cristiano, han dejado en este y en la cultura occidental huellas manifiestas.

5 Para más informaciones sobre el tema, véase Il corpo de Umberto Galimberti. El pensador italiano sostiene que el occidental tiende a establecer naturalmente una barrera entre la mente y el cuerpo, debido a la tradición dualista prevaleciente en su cultura. Para Galimberti, es mayor la implicación del cristianismo en esta particular visión del ser humano, pero, dicha concepción encuentra en realidad su fuente en el pensamiento griego, en especial platónico, siendo la noción de alma para Platón el necesario origen de las abstracciones imprescindibles para el pensamiento. A partir de la traducción griega de la Biblia, el cristianismo, inicialmente muy corpóreo, se dejó poco a poco impregnar por la cultura griega y grandes representantes de la Patrística, en particular Agustín, reelaboraron las nociones platónicas a las cuales fue otorgado un valor soteriológico.

6 Borges dijo al respecto: «La Trinidad [...] parece un caso de teratología intelectual, una deformación que solo el horror de una pesadilla pudo parir. Así lo creo, pero trato de reflexionar que todo objeto cuyo fin ignoramos, es provisoriamente monstruoso». (OC I 210).

7 Porque sabemos que la ley es espiritual; mas yo soy carnal, vendido a sujeción del pecado. Porque lo que hago, no lo entiendo; ni lo que quiero, hago; antes lo que aborrezco, aquello hago (Romanos 7:14).

8 «...] Empero cuando el Hijo del hombre viniere, ¿̨hallará fe en la Tierra?» (Lucas $18: 8)$.

9 Esto es expresado admirablemente por Philonenko en su libro sobre Schopenhauer: «L'existence a soif de l'être, mais l'être a soif d'existence». (Philonenko, 1980:188).

10 «Así que, Pilato volvió a entrar en el pretorio, y llamó a Jesús, y díjole: ¿Eres tú el Rey de los Judíos? [...] Respondió Jesús: Mi reino no es de este mundo: si de este mundo fuera mi reino, mis servidores pelearían para que yo no fuera entregado a los judíos: ahora, pues, mi reino no es de aquí». Cf. Biblia Reina Valera (Juan 18: 33-36).

11 Véase Borges, Carrizo (1982:19).

12 Tal idea deriva de la filosofía de Hume, como lo explica Tasset: «Una vez más no se entiende a Hume. Hume critica la concepción substancialista y estática del Yo de la tradición racionalista. Eso no permite afirmar que niega el Yo. Evidentemente niega el Yo como resultado, pero no como proceso, como interrelación de técnicas de producción de muy diversas cosas: sexualidad, moralidad, y por supuesto también muerte. Desde ahí se entiende mucho mejor su espíritu transgresor: su original tesis se resume en la paradoja según la cual las técnicas de producción del Yo culminan con la disolución de este». Cf. Tasset (1992:165).

13 Se aúnan maravillosamente las características evocadas acerca de las muertes respectivas del joven poeta y del abuelo de Borges en el suicidio del escritor japonés Yukio Mishima, cuya muerte fue tal vez la última y más relevante de sus obras.

14 Se puede muy provechosamente consultar los libros de Cristine Orsini sobre el pensamiento girardiano (Orsini 2018, 1986) 
15 La violencia se concibe como un aprendizaje posibilitado por la tendencia mimética del hombre pues la imitación es clave para todo lo que uno aprende en el decurso de una vida, como el idioma: «Il n'y a rien ou presque, dans les comportements humains, qui ne soit appris, et tout apprentissage se ramène à l'imitation. Si les hommes, tout à coup, cessaient d'imiter, toutes les formes culturelles s'évanouiraient. Les neurologues nous rappellent fréquemment que le cerveau humain est une énorme machine à imiter». (Girard, 1983:15).

16 La crucifixión de Cristo sería el mensaje enviado por Dios a los hombres para que tomaran conciencia de las consecuencias terribles de sus actos, un autosacrificio cuyo propósito era acabar con todo sacrificio (Girard, 1983:3).

17 Philonenko sostiene que, para Schopenhauer, la envidia se origina en la ignorancia. Por mucho que cada hombre lleve en sí todas «las virtualidades de la especie humana», el individuo expresa necesariamente una única dimensión de la especie. Partiendo de este postulado, sería tal vez necesario seguir el sabio ejemplo de Diógenes, quien al toparse con el emperador Alejandro, no deseó para nada ocupar su lugar, sino que prefirió quedarse en su tonel donde podía libremente observar el sol. (Philonenko, 1980:224).

18 Por eso Girard juzga vana la ambición de tener «una idea original»: «Mais est-ce vraiment une idée originale au sens moderne de la nouveauté? La moindre réflexion dissout le semblant d'originalité, pour laisser place à l'imitation, à la mimesis une fois de plus». (Girard, 2007:1395).

19 Algo totalmente distinto ocurre con la justicia eterna a la que antes se aludía, y de la que no se encarga el Estado sino el mundo: «[...] no depende de las instituciones humanas, no está sometida al azar ni al engaño, no es insegura, fluctuante ni errada, sino infalible, firme y segura». Cf. Schopenhauer (2009:410).

20 Véase el artículo que S. Grennblatt escribió para The New Yorker: «Why would a benevolent God permit something so monstrous? [...] Augustine countered that we are all marked, in our very origins, with evil. It is not a matter of particular acts of cruelty or violence, specific forms of social pathology, or this or that person who has made a disastrous choice». (Greenblatt, 2017)

\section{Sobre la autora}

Estudiante de doctorado LSHS (Letras, Ciencias humanas y Sociales), Universidad Clermont Auvernia. Escuela doctoral: IRHIM (Instituto de Historia de las Representaciones y de las ideas en las Modernidades). Sus temas de investigación son Borges, las religiones y culturas, Oriente y Occidente. 